\title{
Aza-Crown Ethers Attached to Dendrimers through
}

\section{Amidoferrocenyl Units}

Blanca González, ${ }^{\dagger}$ Beatriz Alonso, ${ }^{*}{ }^{\dagger}$ José Losada, ${ }^{\ddagger}$ M. Pilar García-Armada, ${ }^{\ddagger}$ and Carmen M. Casado ${ }^{*}+$

Departamento de Química Inorgánica, Facultad de Ciencias, Universidad Autónoma de Madrid, Cantoblanco 28049-Madrid, Spain, and Departamento de Ingeniería Química Industrial, Escuela Técnica Superior de Ingenieros Industriales, Universidad Politécnica de Madrid, 28006-Madrid, Spain beatriz.alonso@uam.es carmenm.casado@uam.es

${ }^{\dagger}$ Universidad Autónoma de Madrid ${ }^{\ddagger}$ Universidad Politécnica de Madrid. 


\section{Supporting Information}

\section{General Considerations.}

Materials and Equipment. All reactions were performed under an inert atmosphere (prepurified Ar) using standard Schlenk techniques. Solvents were dried by standard procedures over the appropiate drying agents and distilled immediately prior to use. The dendritic polyamines DAB-dend- $\left(\mathrm{NH}_{2}\right)_{\mathrm{x}}(\mathrm{x}=$ 4, 8 and 16) were purchased from Aldrich, 1,4-diaminobutane and 1-aza-18-crown-6 from Fluka and 1,1'-ferrocenedicarboxylic acid from Alfa Aesar ${ }^{\circledR}$. These compounds were used without further purification. Triethylamine (Merck) was distilled over $\mathrm{KOH}$ under Ar. All other chemicals were of the best quality commercially available. NMR spectra were recorded on a Bruker AMX-300 and a Bruker DRX-500 spectrometers. MALDI-TOF mass spectra analyses were conducted on a Reflex ${ }^{\mathrm{TM}}$ III Bruker spectrometer. ESI mass spectra were recorded on a "QSTAR Pulsar i" mass spectrometer from Applied Biosystems, equipped with an hybrid analyser QTOF (quadrupole-time of flight). The samples were directly infused into the ESI source using a syringe pump at a flow rate of $10 \mu \mathrm{L} / \mathrm{min}$. Cyclic voltammetric experiments were performed with a BAS CV-50W workstation (Bioanalytical Systems, Inc.). A glassy carbon disk working electrode $\left(0.07 \mathrm{~cm}^{2}\right)$, tungsten counter electrode and saturated calomel reference electrode were fitted to a $5 \mathrm{~mL}$, single-compartment electrochemical cell.

Synthesis of $\mathbf{F c}(\mathbf{C O C l})_{2}$. 1,1'-Ferrocenedicarbonyl chloride was prepared through a procedure described in the literature. (Knobloch, F. W.; Rauscher, W. H. J. Polymer Science 1961, 54, 651.) A mixture of 1,1'-ferrocenedicarboxilic acid ( $8.79 \mathrm{~g}, 0.032 \mathrm{~mol})$, oxalyl chloride (14 ml, $0.160 \mathrm{~mol})$ and pyridine $(0.5 \mathrm{~mL})$ in $140 \mathrm{ml}$ of dry dichloromethane was stirred under $\mathrm{Ar}$ in the dark for 4 hours at room temperature and then refluxed overnight. The reaction mixture was evaporated to dryness under reduced pressure and the residue extracted repeatedly with hexane. The solvent of the filtrate was removed under reduced pressure to give a red solid $(9.20 \mathrm{~g}, 92 \%)$ which was kept under Ar. 
Supporting Information

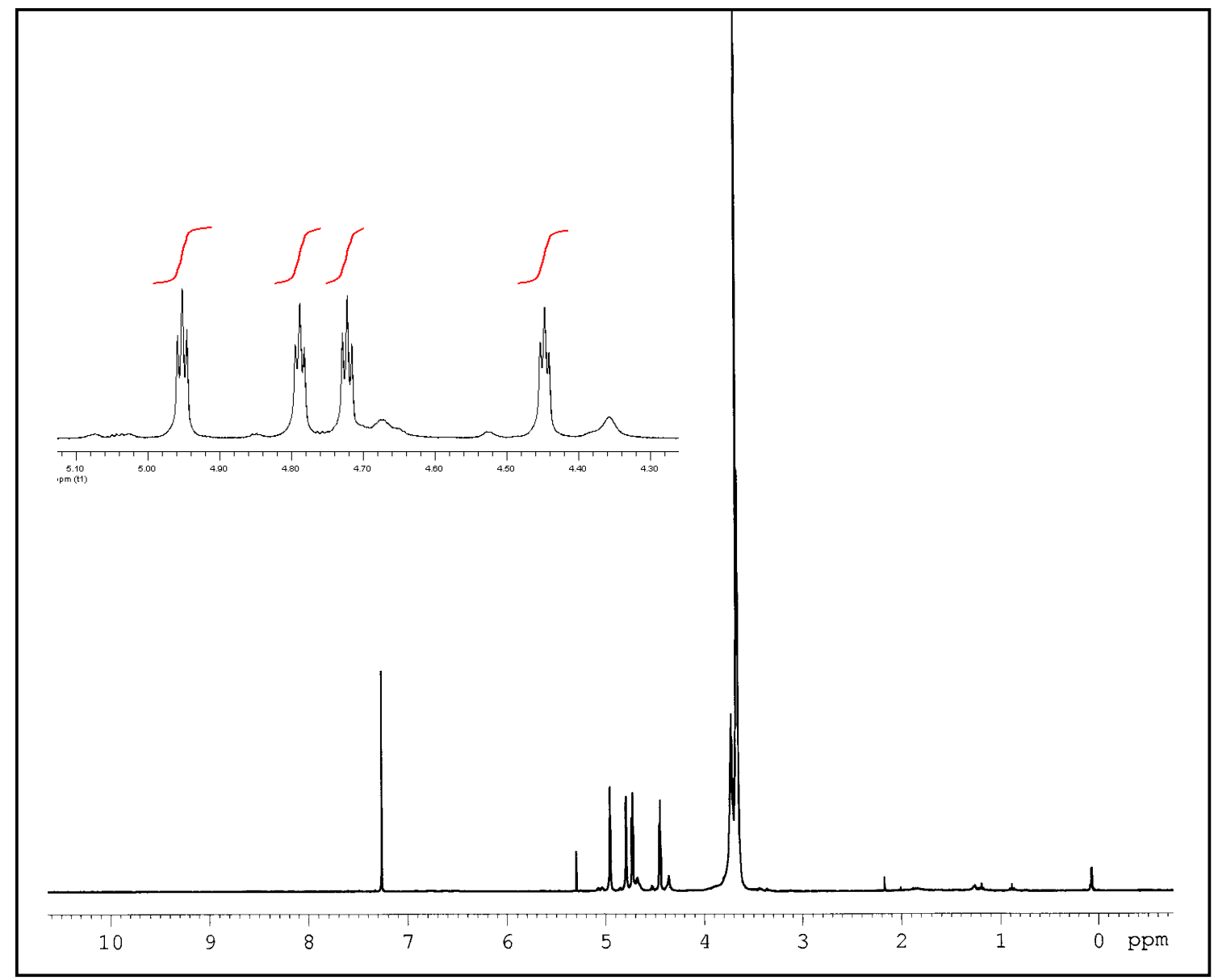

Figure S1. ${ }^{1} \mathrm{H}$ NMR spectrum of $1\left(300 \mathrm{MHz}, \mathrm{CDCl}_{3}\right)$. 
Supporting Information

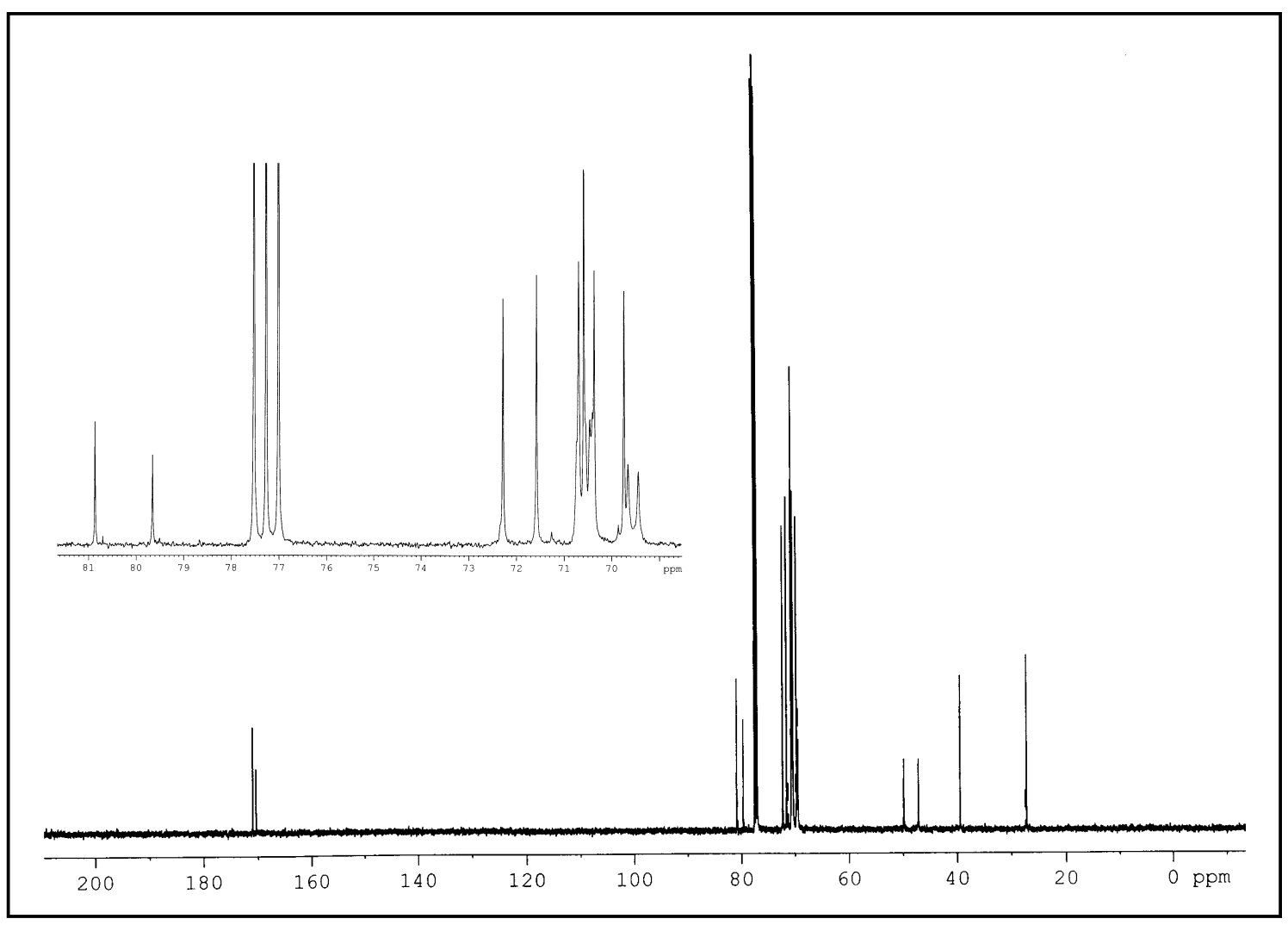

Figure S2. ${ }^{13} \mathrm{C}\left\{{ }^{1} \mathrm{H}\right\} \mathrm{NMR}$ spectrum of $2\left(125.77 \mathrm{MHz}, \mathrm{CDCl}_{3}\right)$. 
Supporting Information

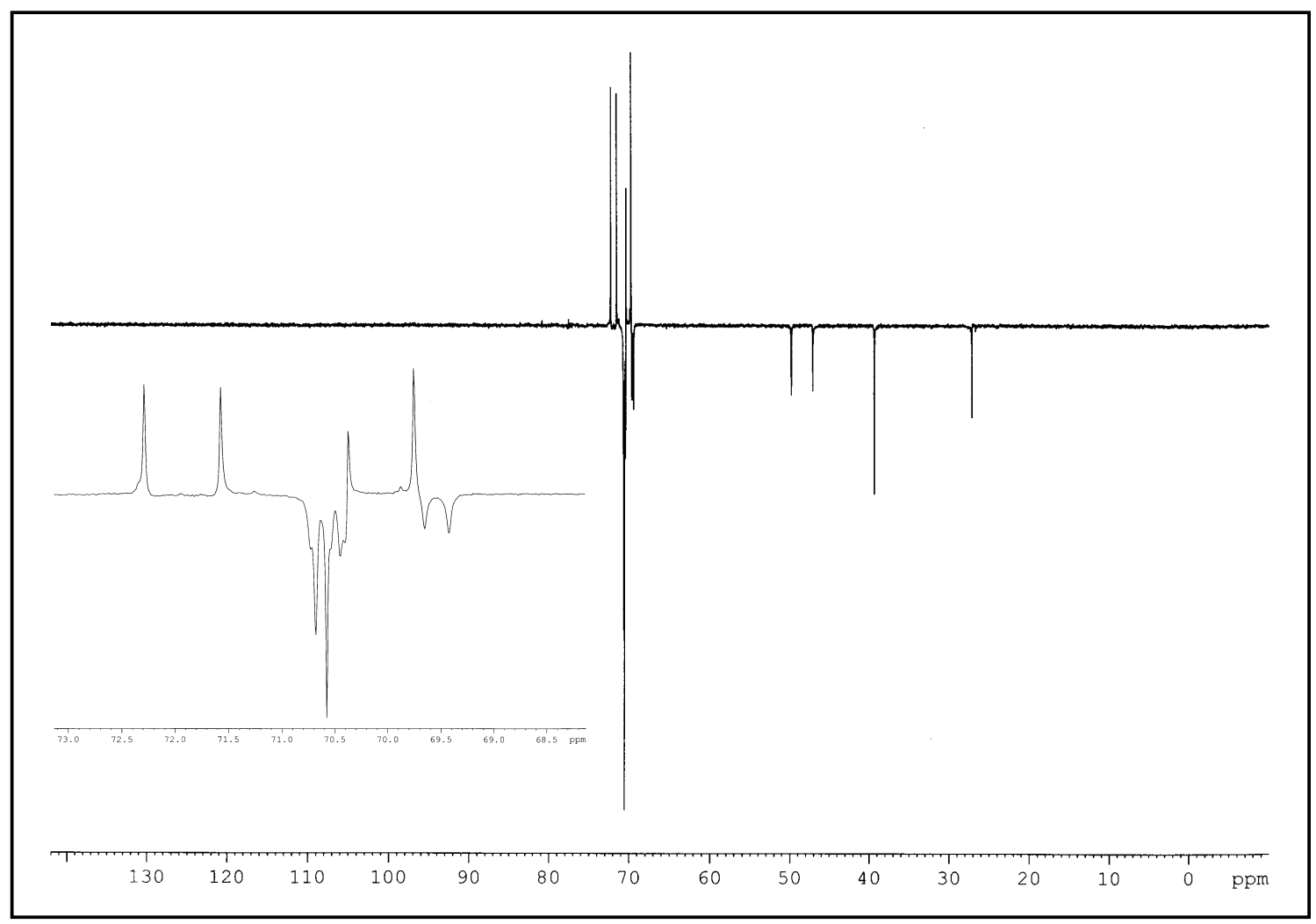

Figure S3. ${ }^{13} \mathrm{C}\left\{{ }^{1} \mathrm{H}\right\}$ DEPT NMR spectrum of $2\left(125.77 \mathrm{MHz}, \mathrm{CDCl}_{3}\right)$. 
Supporting Information
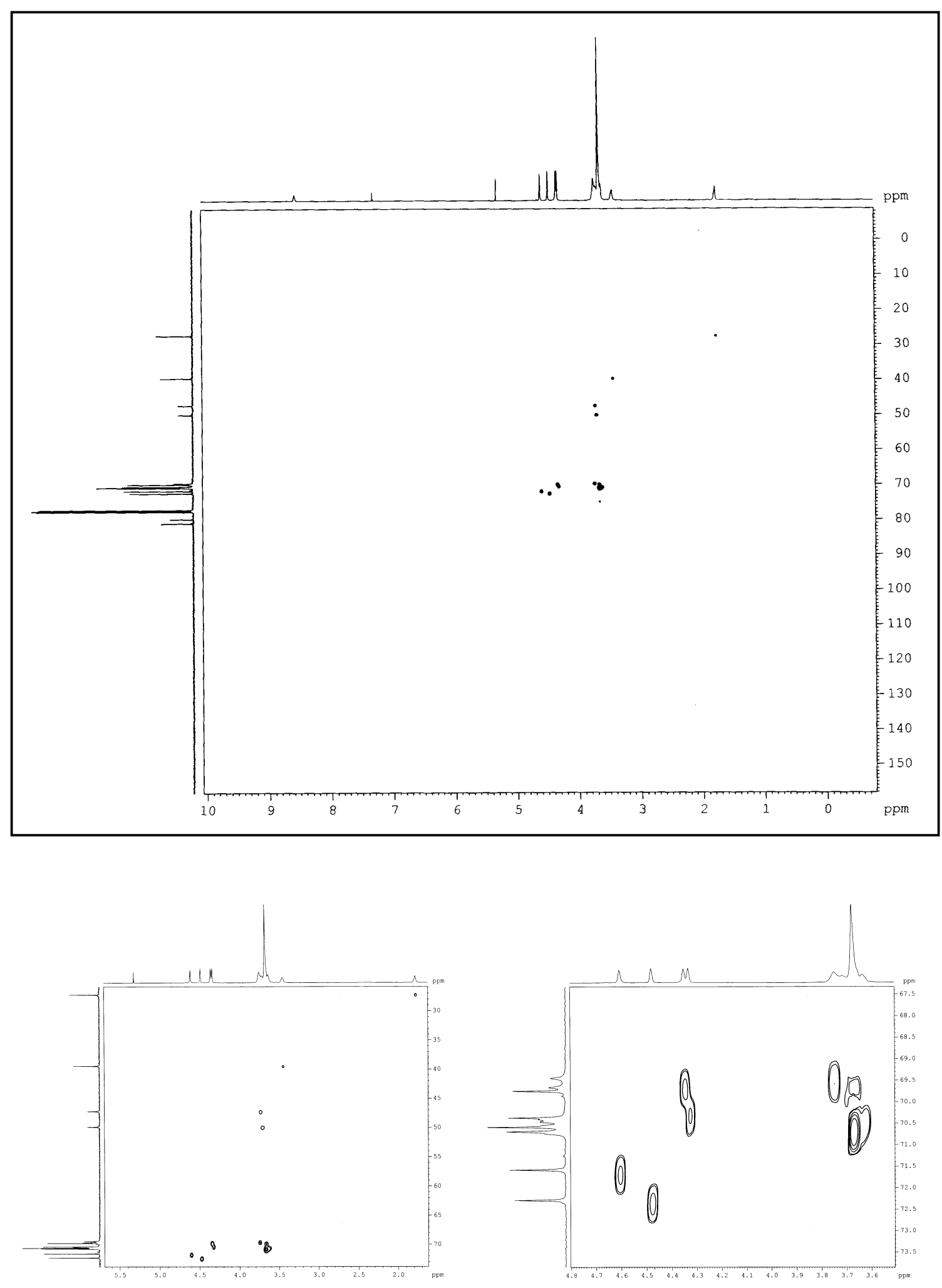

Figure S4. ${ }^{13} \mathrm{C}-{ }^{1} \mathrm{H}$ HMQC NMR spectrum of $2\left(\mathrm{CDCl}_{3}\right)$. 


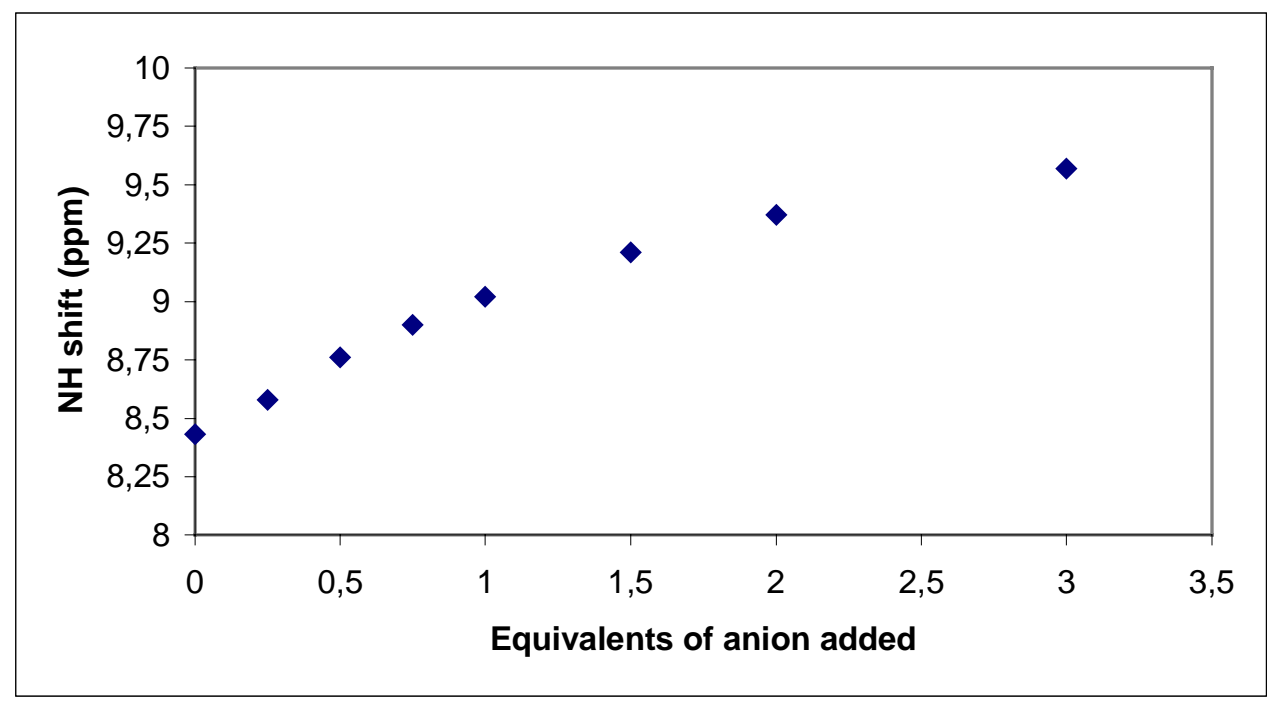

Figure S5. ${ }^{1} \mathrm{H}$ NMR titration curve for 2 with $\mathrm{F}^{-}$in acetone- $\mathrm{d}_{6}(500 \mathrm{MHz})$. 
Supporting Information
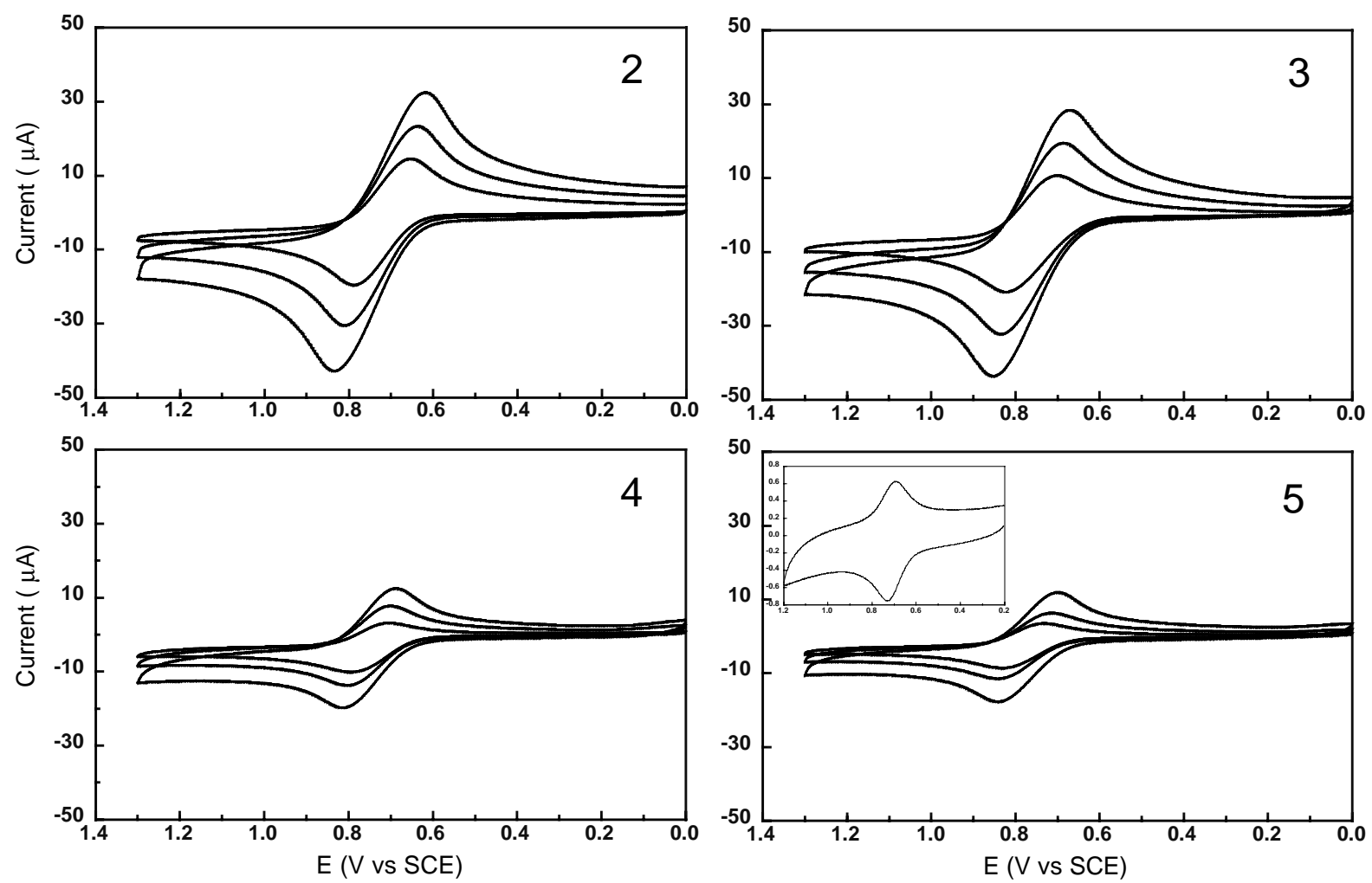

Figure S6. Representative cyclic voltammograms obtained with a GC working electrode $\left(0.07 \mathrm{~cm}^{2}\right)$ in solutions containing dendrimers 2-5 (1 mM in ferrocene centers) and TBAH (0.1 M) in $\mathrm{CH}_{2} \mathrm{Cl}_{2}$. $\mathrm{Scan}$ rates: $0.10,0.25$ and $0.50 \mathrm{~V} \mathrm{~s}^{-1}$. Inset: Cyclic voltammogram of a Pt electrode $\left(0.02 \mathrm{~cm}^{2}\right)$ modified with a film of $\mathbf{5}$, measured in $\mathrm{CH}_{2} \mathrm{Cl}_{2} / \mathrm{TBAH}$ at $0.10 \mathrm{~V} \mathrm{~s}^{-1}$. 